\title{
Resgate e reabilitação de um aluno autista no ensino Fundamental com uso de tecnologias de informação e comunicação
}

\author{
Reisla Rodrigues ${ }^{1}$, Sean Siqueira \\ reisla.rodrigueseuniriotec.br, seaneuniriotec.br \\ Departamento de Informática Aplicada \\ Universidade Federal do Estado do Rio de Janeiro (UNIRIO) \\ Rio de Janeiro - RJ - Brasil
}

\begin{abstract}
For autistic people, difficulties in social interaction and communication difficulties create almost unbridgeable obstacles to accompany the recommended age series in a regular school without the specialized psych pedagogical and technological support. Issues classified as lack of maturity or difficulties of communication and expression or lack of social repertoire, often overlap with the content that the student possesses, generating a vicious cycle that holds him in a stage or academic phase, hindering the development and acquisition of new skills. In this article we describe an action-research on the use of educational and assistive technologies to support and rehabilitate a 12-year-old elementary school student, diagnosed late with autism spectrum disorder, allowing his reinclusion in school Regular.
\end{abstract}

Resumo. Para os autistas as dificuldades na interação social e a dificuldade de comunicação, criam obstáculos quase intransponíveis para acompanhar a série recomendada para a idade numa escola regular sem o apoio psicopedagógico e tecnológico especializado. Questões classificadas como falta de maturidade ou dificuldades de comunicação e expressão ou a falta de repertório social, muitas vezes se sobrepõem ao conteúdo que o aluno possui, gerando um ciclo vicioso que o prende em uma etapa ou fase acadêmica, dificultando o desenvolvimento e aquisição de novas habilidades. Neste artigo descrevemos uma pesquisa-ação do uso de tecnologias educacionais e assistivas para apoiar e reabilitar um aluno do ensino fundamental, de 12 anos, diagnosticado tardiamente com transtorno do espectro autista, permitindo a sua reinclusão na escola regular.

\section{Introdução}

Para os autistas alguns aspectos de suas deficiências, em especial a dificuldade de comunicação, a dificuldade de interação social e a dificuldade de controle sensorial, criam obstáculos quase intransponíveis para acompanhar a escola regular na série recomendada para a idade e precisam ser trabalhados para permitir que a criança se sinta confortável e segura para explorar novas rotinas e ambientes.

A proposta de inclusão de autistas no sistema acadêmico regular, promovida pela Lei 12.764 (2012) trouxe à tona algumas deficiências deste sistema que atingem não só os autistas,

\footnotetext{
1 “O presente trabalho foi realizado com apoio da Coordenação de Aperfeiçoamento de Pessoal de Nível Superior - Brasil (CAPES) - Código de Financiamento 001

"This study was financed in part by the Coordenação de Aperfeiçoamento de Pessoal de Nível Superior - Brasil (CAPES) - Finance Code 001"
} 
VIII Congresso Brasileiro de Informática na Educação (CBIE 2019)

Anais do XXV Workshop de Informática na Escola (WIE 2019)

mas também crianças que encontram dificuldades em acompanhar o processo imposto pelo sistema de serialização da escola.

Questões classificadas como falta de maturidade ou dificuldades de comunicação e expressão ou a falta de repertório social, muitas vezes se sobrepõem ao conteúdo que o aluno possui e acabam por retê-lo em uma fase que ele já pode ter dominado, obrigando-o a conviver em uma turma ainda menos estimulante e mais imatura, causando ainda maior retrocesso na interação social. (Beyer, 2013).

Com uma incidência crescente nos últimos anos o Transtorno do espectro autista (TEA) já atinge 1 em cada 55 crianças em idade escolar nos Estados Unidos, com base em pesquisa realizada pelo Centers for Disease Control and Prevention (CDC) em 2013. (APA, 2014). No Brasil não temos pesquisas sobre a incidência, mas estima-se que este número não seja muito diferente. Além do número crescente de casos relatados, há ainda um grande percentual de crianças consideradas problemáticas que nunca chegam a conseguir uma avaliação ou diagnóstico. (Mello, et al., 2013)

Como os sintomas do transtorno são variados, tanto em incidência quanto na gravidade, o diagnóstico de TEA se torna um processo difícil e controverso, passando por diversos profissionais que nem sempre chegam a um consenso. (Santos, 2016)

Quanto mais tardio for a percepção do autismo maior será a dificuldade de estabelecer uma linha terapêutica, pois além das deficiências do transtorno ainda será necessário lidar com as suas consequências no processo cognitivo e social já desenvolvido pela criança e com as comorbidades que possam surgir em decorrência de experiências traumáticas.

Quando o diagnóstico é tardio, geralmente após a entrada na escola, a criança já está estigmatizada por diversos problemas de relacionamento e dificuldades cognitivas que impactam diretamente no seu desempenho acadêmico. Em muitos casos, além de um tratamento para acompanhar a criança autista, é necessário a intervenção pedagógica para resgatá-la de um ciclo vicioso que a prende em uma etapa ou fase acadêmica, dificultando o desenvolvimento e aquisição de novas habilidades. (GREENSPAN \& WIEDER, 2008)

Reconhecer e acompanhar o autismo, identificando as habilidades e dificuldades da criança e traçar um planejamento de atividades e ações que possam favorecer seu desenvolvimento cognitivo e social, é a melhor forma de diminuir os impactos da deficiência. (Brasil. Ministério da Saúde. , 2014)

Os recursos tecnológicos podem atuar como um ferramental importante, tanto para o diagnóstico quanto para planejar e acompanhar a evolução dos alunos com necessidades educacionais especiais, recomendando e oferecendo objetos de aprendizagem que permitam seguir em uma trajetória e ritmo individualizado. Com reavaliações constantes o aluno pode avançar ou retroceder dentro de uma trajetória, no seu ritmo e de acordo com a sua própria evolução. E o que a tecnologia nos permite hoje é automatizar este processo tornando-o mais lúdico e acessível.

A utilização de tecnologias educacionais e assistivas que permitam multiplicar as ações e formas de aprendizagem, dando ao educador mais liberdade de ação como mediador do processo de aprendizagem, possibilitam a adaptação do sistema de ensino padronizado para um processo individualizado com foco no aluno. (Passerino \& Santarosa, 2006)

Esta pesquisa buscou nas tecnologias digitais de informação e comunicação o ferramental para apoiar a implementação de uma educação inclusiva para alunos com Transtornos do Espectro Autista dentro do sistema educacional regular.

Aqui relatamos as soluções já disponíveis utilizadas para avaliar e recomendar 
conteúdos, favorecer e intermediar a comunicação e a expressão, e auxiliar o autista a explorar e controlar seus interesses e habilidades. Com o objetivo de modelar uma estratégia de uso individualizada que permita auxiliar alunos de grau leve ou moderado de autismo, a desenvolverem o seu potencial, reabilitando-os ao sistema acadêmico, tornando-os aptos a prosseguir no sistema regular de ensino, compartilhando o desenvolvimento e a convivência com crianças de mesma idade.

\section{Métodos:}

Esta pesquisa-ação propõe-se a explorar as possibilidades do uso intensivo da tecnologia para resgatar o desenvolvimento acadêmico de um aluno do ensino fundamental, de 12 anos, diagnosticado tardiamente com TEA, com desenvolvimento psicopedagógico considerado deficiente pela escola de origem ao final do $5^{\circ}$ ano do ensino fundamental I.

Desenvolver um estudo dentro dos padrões da pesquisa-ação, segundo (BARBIER, 2002), provoca o desenvolvimento de uma concepção dos processos de mudança como elo entre o processo de elaboração teórica e a elaboração de novas práticas coletivas.

Seguindo a abordagem DIR/Floortime, o histórico da criança foi levantado para confirmação do TEA e para identificação das raízes de suas dificuldades (GREENSPAN \& WIEDER, 2008). A criança já havia experimentado um retrocesso no $1^{\circ}$ ano do fundamental, devido a problemas de adaptação e maturidade que inviabilizaram a alfabetização na idade correta. A partir dos "problemas" relatados pela professora na alfabetização, foi iniciada a investigação para o diagnóstico de autismo.

Como o ano ainda era 2007, e o diagnóstico do autismo ainda era um processo difícil, a criança foi retida no $1^{\circ}$ ano do ensino fundamental passando a frequentar uma turma com idades inferiores à sua. Este processo trouxe mais prejuízos às relações sociais fragilizadas pelos déficits do autismo.

Nos anos 3 anos seguintes, com apoio psicopedagógico especializado, o aluno conseguiu acompanhar a turma do fundamental com desempenho razoável até o $5^{\circ}$ ano, o último ano do ensino fundamental, quando a preparação para a transição para o ensino fundamental II criou uma alteração na rotina do aluno. Neste último ano, o aluno não conseguiu alcançar o desempenho esperado nos testes padronizados da escola.

Apesar de todas as evidências de TEA, e do apelo da psicopedagoga que o acompanhava, a escola permaneceu irredutível sobre a reprovação do aluno, submetendo-o a constrangimentos ao anunciar para turma, durante a cerimônia de formatura, que "conforme previsto no início do ano" o aluno não conseguiu ser aprovado.

No início do ano de 2014, houve uma tentativa de reinclusão do aluno no $6^{\circ}$ ano de um novo colégio, ainda um ano defasado em relação a idade esperada para a série, mas já com um diagnóstico de Autismo de grau moderado, com visível deficiência de conteúdos cognitivos, além de resistente a iniciar relações sociais e até mesmo de frequentar a escola.

A nova escola, um pouco mais preparada para lidar com os aspectos especiais da inclusão escolar de autistas, exigiu a contratação de uma mediadora que acompanharia o aluno em tempo integral durante as aulas. Apesar do alto custo, tanto financeiro quanto social ao aluno, mesmo com o apoio da mediadora, já no primeiro bimestre foi evidenciado que o aluno não conseguiria acompanhar a turma, necessitando de uma intervenção um pouco mais efetiva e profunda.

O estudo foi realizado com apoio dos pais, que optaram por retirar o aluno da escola e iniciar um processo de resgate e reabilitação psicopedagógica, em casa, utilizando 
intensivamente recursos tecnológicos, ambientes virtuais de aprendizagem (AVA) e comunicação digital. Apesar dos pais terem uma rotina de trabalho no escritório, a mãe, analista de sistemas com formações pedagógicas, disponibilizou um período de um mês de férias para acompanhar e apoiar o processo e negociou um horário de trabalho flexível que permitia, por exemplo, almoçar em casa e eventualmente trabalhar remotamente.

No primeiro mês fora da escola, junho de 2014, foi adotada uma rotina intensiva para levantar todos os problemas e dificuldades da criança. Em sessões diárias, de 4 a $6 \mathrm{~h}$, com intervalos regulares para lanches e atividades de lazer, as atividades eram intercaladas, mudando-se o assunto ou a atividade da criança quando a motivação começava a decair, o que ocorria, dependendo do interesse, em períodos não maiores que 2 horas.

As atividades pedagógicas eram feitas em sua maioria no ambiente virtual de aprendizagem Khan Academy, (Khan, 2013) cobrindo as disciplinas de matemática e ciências. Este ambiente permitiu que todo o conteúdo de matemática fosse reavaliado através de desafios e gamificação. Dúvidas e dificuldades foram evidenciadas e tratadas, independente da série escolar do conteúdo.

As atividades de leitura, em livros físicos, eram complementadas por buscas na internet usando o Google e a Wikipedia para exploração de locais geográficos, busca de imagens e vídeos ilustrativos de termos e assuntos citados e para aprofundamento de assuntos específicos. A produção de textos foi implementada através de um editor de textos produzido com os comentários e pesquisas sobre os livros lidos, utilizando-se intensivamente de corretores ortográficos,

Também foram exploradas as pesquisas em programação utilizando o aplicativo ProgramAê. Estas atividades fora do currículo padrão permitiam abrir o horizonte de assuntos, gerando um repertório que era estimulado e utilizado nas conversas com os tutores e mediadores, além de outras crianças.

Após o primeiro mês, a criança já tinha domínio da rotina e dos ambientes de aprendizagem. Neste momento foi marcado o primeiro "milestone" do projeto, ou seja, a posição que a criança estava em cada uma das atividades que estavam sendo desenvolvidas.

Um protocolo de comunicação virtual, através do Skype, foi estabelecido para progressivamente ir distanciando a presença física dos tutores.

Do segundo mês, agosto, em diante a presença física da tutora já não era tão disponível durante o dia. A criança ficava com uma babá que não conhecia de informática no período da manhã, enquanto os irmãos estavam na escola. No almoço algumas atividades eram checadas. Apesar de não frequentar a escola, nas atividades da tarde, o contato com outras crianças era estimulado não só com seus irmãos, de 14 e 15 anos, mas também em atividades esportivas e sociais. A noite, as atividades do dia eram revisadas, seguidas de um período de organização do dia seguinte e um tempo de leitura antes de dormir.

Apesar da disponibilidade da presença da tutora ter diminuído, a presença virtual através de conversas por Skype continuou intensa. Havia pelo menos 2 ligações por dia, inicialmente começadas pela tutora, mas com o passar do tempo, a criança passou a ligar quando encontrava algum obstáculo nas atividades. A comunicação por chat também era intensa, com o desenvolvimento da linguagem escrita e melhora no vocabulário.

Esta comunicação virtual e constante também foi importante para a criança desenvolver a segurança de que seria amparada caso encontrasse dificuldade e de que teria apoio e direcionamento, mesmo estando eventualmente sozinha. E também para compensar um pouco a falta da interação social da escola. 
VIII Congresso Brasileiro de Informática na Educação (CBIE 2019)

Anais do XXV Workshop de Informática na Escola (WIE 2019)

Sábados e Domingos eram dias livres, com atividades de lazer e atividades ao ar livre, onde as relações interpessoais eram monitoradas com outras crianças da mesma idade. formas:

Semanalmente, no final do Domingo, o avanço do trabalho era avaliado de duas

- um relatório do Khan Academy, informando o tempo e as atividades desenvolvidas na plataforma, e

- uma apresentação do livro ou assunto da semana, que era concluído com um extenso post no blog.

E ao final era feito um planejamento de assuntos ou livro para a próxima semana.

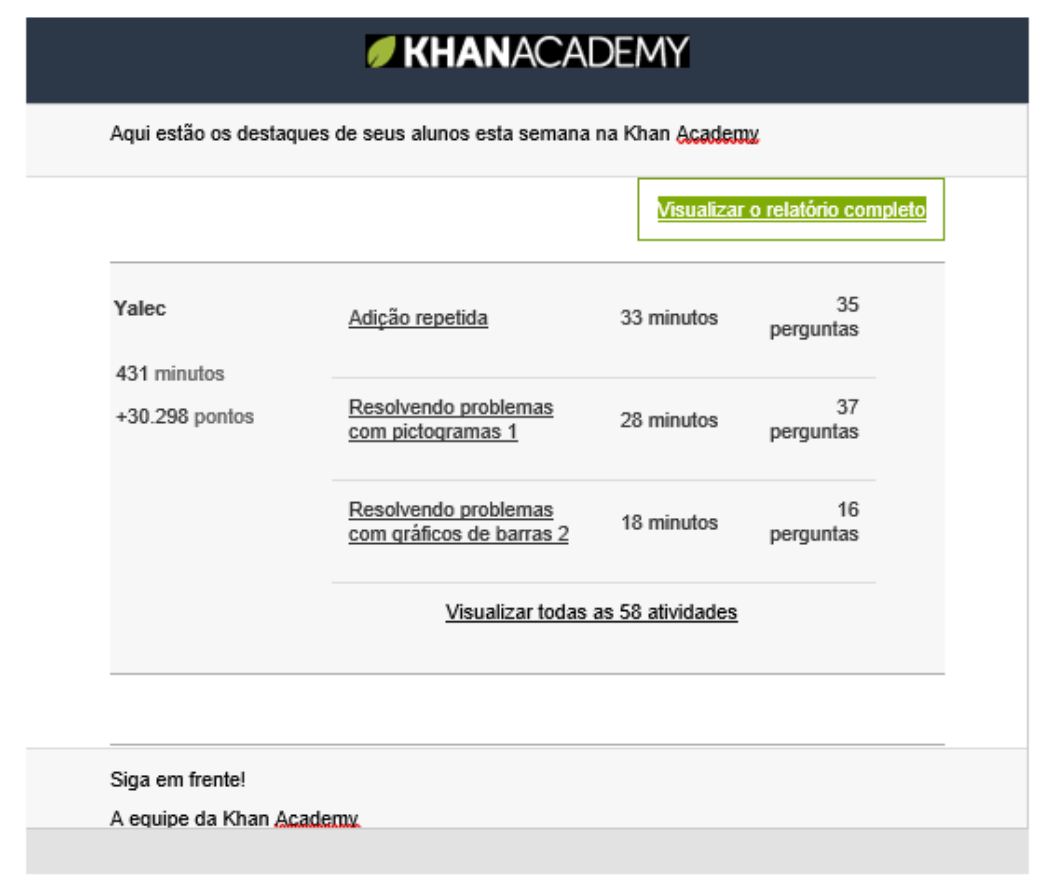

Figura 1- Relatório Semanal Khan Academy

Em agosto e setembro, o avanço foi evidente tanto nos relatórios quanto na comunicação e desenvoltura do comportamento da criança. O progresso em leitura foi notável, com a leitura, interpretação e exploração do conteúdo, em média de um livro por semana. Em matemática foi alcançado o domínio de todo o conteúdo equivalente ao $5^{\circ}$ ano, tanto em álgebra quanto em geometria. Alguns outros assuntos como ciências ou estudos sociais, o vocabulário foi incrementado e conceitos avançados de ciências, ética e filosofia já haviam sido discutidos. Um curso básico de programação por blocos já havia sido completado e a criança estava iniciando a programação básica em Java script.

No final do quarto mês, em outubro/novembro, começamos a ter alguns problemas em relação a motivação. O domínio da matemática do $6^{\circ}$ ano já havia sido alcançado e ele começava a explorar conteúdos mais avançados. Mas a criança sentia falta dos amigos e da interação da escola.

Implementamos uma nova atividade, o vídeo game. Começamos com alguns jogos leves e a interação online controlada. O console era um Xbox 360, e o tempo foi restrito a $2 \mathrm{~h}$ por dia, à tarde, quando os irmãos estavam em casa, o que forçava necessariamente a interação entre eles para compartilhar o tempo e negociar regras de uso do jogo.

Com a entrada do vídeo game conseguimos novamente aumentar o repertório para a 
VIII Congresso Brasileiro de Informática na Educação (CBIE 2019)

Anais do XXV Workshop de Informática na Escola (WIE 2019)

interação, algumas gírias e palavras não tão boas foram inseridas no vocabulário, mas conseguimos um novo estímulo para as atividades rotineiras.

No final de novembro começamos a planejar a reentrada na escola.

\section{Resultados e Discussão:}

A aproximação com a nova escola foi feita com cuidado, expondo a situação do aluno e amparado pelo laudo de TEA assinado por 2 psicólogos e respaldados legalmente pela Lei de Diretrizes e Bases da Educação (9.394/96), que em seu artigo 24, inciso II alínea c, permite a escola reclassificar o aluno de acordo com a capacidade e conhecimentos adquiridos em um programa de aceleração de estudos.

Após os testes aplicados ao final de novembro, a escola aceitou a matrícula do aluno, em caráter experimental, no $7^{\circ}$ ano do ensino fundamental, com a proposta de reavaliá-lo ao final do $1^{\circ}$ bimestre de aulas. Também foi negociado que, em alguns casos, poderiam ser aplicados testes adaptados ou com acompanhamento de um auxiliar para evitar a dispersão e a pressão dos testes coletivos padrão. Estes recursos não precisaram ser utilizados para não comprometer a socialização do aluno na turma.

No ano seguinte, em fevereiro, o aluno reiniciou na escola, no $7^{\circ}$ ano, onde reencontrou parte dos colegas que cursaram com ele o $5^{\circ}$ ano. A readaptação foi tranquila e o aluno conseguiu acompanhar com sucesso a evolução da turma. O desenvolvimento da linguagem, assim como da interação social, foi bastante beneficiado pelo aumento da autoestima, pelo domínio dos conteúdos e pelo desenvolvimento de repertório e vocabulário compatível com as crianças da mesma idade.

O apoio tecnológico continuou a ser utilizado paralelamente ao trabalho da escola, tanto no $7^{\circ}$ ano quanto nos anos seguintes do ensino fundamental.

Muito além dos resultados alcançados no resgate da defasagem escolar, reabilitando o aluno a inclusão na escola regular, a experiência trouxe resultados muito mais amplos nas dificuldades típicas do autismo.

Os aspectos limitantes do autismo foram bem trabalhados permitindo que a criança se sentisse confortável e segura para explorar novas rotinas e ambientes.

Os recursos tecnológicos utilizados, apesar de não oferecerem nenhuma adaptação especial para o autismo, foram fundamentais no processo de aceleração que a criança foi submetida. Sem o uso de tecnologia este trabalho não seria possível, tanto pela organização e disponibilização de conteúdos quanto pela motivação da criança para manter uma rotina reforçada de estudos.

A simples disponibilidade de acesso a internet abre uma porta para a educação, permitindo o acesso instantâneo a atividades e conteúdos diversificados, a exploração e pesquisa de assuntos complementares além de um incremento na motivação e no interesse da criança nos assuntos explorados.

O ambiente virtual além de estimulante, permite a simulação e a interação social de maneira controlada, filtrando-se os aspectos de comunicação e expressão corporal que normalmente são difíceis para os autistas, como a atenção compartilhada (AC) e intenção de atenção compartilhada (IAC) que são um conjunto gestual desenvolvido na infância para promover a interação social e solicitar a atenção de outro indivíduo para compartilhar uma atividade. Como os indivíduos do espectro autista, manifestam uma clara deficiência na aquisição deste gestual de comunicação, a mediação do ambiente virtual na comunicação permite incrementar o vocabulário e o repertório, minimizando as deficiências inclusive nas 
VIII Congresso Brasileiro de Informática na Educação (CBIE 2019)

Anais do XXV Workshop de Informática na Escola (WIE 2019)

interações sociais não virtuais.

Outro aspecto importante desenvolvido neste trabalho foi a autoestima. A criança autista incluída em um sistema de ensino regular está sempre em uma situação de desvantagem, com suas deficiências constantemente em evidência. Ao promover um processo de aprendizagem e encontrar assuntos e atividades que ela possa dominar e em alguns casos até superar o conhecimento de outras crianças típicas (não autistas), permite que a criança ancore sua personalidade em seu potencial e nas suas habilidades, e não apenas em suas deficiências. Esta mudança na visão, da deficiência para o potencial, gera uma mudança de atitude que, além de elevar a autoestima, provoca e estimula o desenvolvimento das habilidades e a abertura para o aprendizado por toda a vida.

\section{Conclusões}

Quando pensamos em inclusão escolar de autismo devemos reavaliar o processo de adaptação para desvincular as atividades cognitivas da interação social, permitindo que o indivíduo com TEA possa, ao mesmo tempo, desenvolver o processo cognitivo e ter suporte para o desenvolvimento dos processos de comunicação e interação social.

Ao inserir mecanismos não sociais de aprendizagem dos aspectos cognitivos, como ler, escrever, calcular e pensar logicamente, promovidos pelos ambientes tecnológicos, permite que os indivíduos com TEA possam desenvolver as atividades cognitivas em igualdade de condições, com desempenho igual ou superior aos indivíduos típicos.

Ao mesmo tempo que os ambientes tecnológicos também podem ser utilizados para fornecer apoio no aprendizado da interação social, que precisam ser preparados e treinados. A comunicação mediada por tecnologia fornece um ambiente seguro para o indivíduo com TEA se expressar e experimentar a interação social de forma controlada.

A comunicação por chat ou outras ferramentas virtuais de comunicação, permite o desenvolvimento da expressão e da interação através da comunicação e o desenvolvimento de um vocabulário mais expressivo, abstraindo de outros canais de comunicação utilizados sincronamente durante a interação física com outros indivíduos.

O uso de tecnologia na educação de autistas, fornecendo apoio assistivo nas deficiências sociais, segurança no desenvolvimento cognitivo e um consequente desenvolvimento da autoestima, permite desenvolver também os aspectos socioemocionais, como colaborar, trabalhar em time, ter abertura ao novo, ser criativo, ouvir diferentes pontos de vista e respeitar, ter tolerância e empatia, tornando a rotina da sala de aula mais pacífica e produtiva.

\section{Referências}

APA, 2014. Manual diagnóstico e estatístico de transtornos mentais-DSM-V. Porto Alegre: Artmed.

BARBIER, R., 2002. A pesquisa-ação.. Brasília, Plano Editora.

Beyer, H. O., 2013. Inclusão e Avaliação na Escola. porto alegre: mediação.

Brasil. Ministério da Saúde. , 2014. Diretrizes de Atenção à Reabilitação da Pessoa com Transtornos do Espectro do Autismo (TEA) / Brasil. Ministério da Saúde. Secretaria de Atenção à Saúde. Departamento de Ações Programáticas Estratégicas.. Brasília: Ministério da Saúde.

Brasil, 2012. LEI 12.764, DE 27 DE DEZEMBRO DE 2012. Institui a Política Nacional de 
VIII Congresso Brasileiro de Informática na Educação (CBIE 2019)

Anais do XXV Workshop de Informática na Escola (WIE 2019)

Proteção dos Direitos da Pessoa com Transtorno do Espectro Autista., s.1.: Brasil.

Ferreira, W. et al., 2018. Panorama das Publicações Nacionais sobre Autismo, Educação e Tecnologia. Fortaleza, s.n.

Gabriel, M., 2013. Educar - a revolução digital na educação. São Paulo: Saraiva.

GREENSPAN, S. \& WIEDER, S., 2008. DIR ${ }^{\circledR} /$ Floortime $^{\mathrm{TM}}$ Model, s.1.: The International Council on Developmental and Learning Disorders.

Khan, S., 2013. Um mundo, uma escola ("The One World schollhouse"). Rio de Janeiro: Intrínseca.

Mello, A. M. S. R. d., Andrade, M. A., Ho, H. \& Souza Dias, 2013. Retratos do autismo no Brasil, São Paulo: AMA - Associação de Amigos do Autista.

Passerino, L. M. \& Santarosa, L. M. C., 2006. Possibilidades da mediação tecnológica na inclusão escolar de autistas. Campo Grande, MS, SBC, pp. 256-264.

Santos, V. L. P. d., 2016. Autismo : vivências e caminhos [livro eletrônico]. São Paulo: Blucher. 